\title{
A Brief Comment on Atom Probe Tomography Applications
}

\author{
Jae-Bok Seol ${ }^{1, *}$, Young-Tae Kim², Chan-Gyung Park ${ }^{1,2, *}$ \\ ${ }^{1}$ National Institute for Nanomaterials Technology, Pohang University of Science and Technology (POSTECH), Pohang 37673, Korea \\ ${ }^{2}$ Department of Materials Science and Engineering, Pohang University of Science and Technology (POSTECH), Pohang 37673, Korea
}

\author{
*Correspondence to: \\ Seol JB, \\ Tel: +82-54-279-0220 \\ Fax: +82-54-279-0249 \\ E-mail: jb_seol@postech.ac.kr \\ Park CG, \\ Tel: +82-54-279-2139 \\ Fax: +82-54-279-0249 \\ E-mail: cgpark@postech.ac.kr
}

Received September 27, 2016

Revised September 27, 2016

Accepted September 27, 2016

\begin{abstract}
Atom probe tomography is a time-of-flight mass spectrometry-based microanalysis technique based on the field evaporation of surface atoms of a tip-shaped specimen under an extremely high surface electric field. It enables three-dimensional characterization for deeper understanding of chemical nature in conductive materials at nanometer/ atomic level, because of its high depth and spatial resolutions and ppm-level sensitivity. Indeed, the technique has been widely used to investigate the elemental partitioning in the complex microstructures, the segregation of solute atoms to the boundaries, interfaces, and dislocations as well as following of the evolution of precipitation staring from the early stage of cluster formation to the final stage of the equilibrium precipitates. The current review article aims at giving a comment to first atom probe users regarding the limitation of the techniques, providing a brief perspective on how we correctly interprets atom probe data for targeted applications.
\end{abstract}

Key Words: Atom probe tomography, Three-dimensional characterization

\section{INTRODUCTION}

Atom probe tomography (APT) has been widely applied to wide range of materials including metals, metal alloys, ceramics, and semiconductors for going through threedimensional distribution, segregation or partitioning of trace elements. For example, this high-resolution characterization technique helps to understand diffusion of light element (e.g., boron and carbon), segregation at interfaces, gradients in chemical composition between second phase precipitate particles and their host matrix phase (Bang et al., 2015; Kim et al., 2015; Park et al., 2015; Seol et al., 2010, 2011, 2012, 2013a, 2013b, 2013c, 2016a). Recent significant advances of pulsedlaser APT system now enable analysis of biological material to obtain 3D spatial distributions of cellular ions (Gordon \& Joester, 2011; Karlsson et al., 2015; Narayan et al., 2012).

By applying high positive voltage to a very sharp specimen having a radius of curvature under $50 \mathrm{~nm}$, the atoms at the very surface of specimen are field-evaporated almost atomby-atom and atomic-layer after atomic-layer. The field- evaporated atoms are ionized on tip surface and accelerated towards a position sensitive detector that records their time of flight (ToF) and impact position, simultaneously. The ToF of the ion is directly related to its kinetic energy and potential energy, so by equating the two energies, the mass-to-charge ratio $(\mathrm{m} / \mathrm{n})$ of the ion can be determined as below and it enables the identification of elemental species. A 3D elemental map can be reconstructed from the collected data. More details of principle are described in following reference (Gault et al., 2012; Kelly \& Miller, 2007; Larson et al., 2013b; Miller \& Forbes, 2014).

$$
\left(\frac{m}{n}\right)=2 e\left(\alpha V_{d c}+\beta V_{p}\right)\left(\frac{1}{v}\right)^{2}=2 e\left(\alpha V_{d c}+\beta V_{p}\right)\left(\frac{t}{l}\right)^{2} \cdots \cdots(1)
$$

The better utilization of APT could be achieved by four rapid developments: (1) The high spatial resolution of better than $0.3 \mathrm{~nm}$ and high analytical sensitivity as good as 10 atomic ppm are achievable by both position sensitive detector and local electrode. It made up for the weak points of two-

(a) This is an open-access article distributed under the terms of the Creative Commons Attribution Non-Commercial License (http://creativecommons.org/licenses/by-nc/4.0) which permits unrestricted noncommercial use, distribution, and reproduction in any medium, provided the original work is properly cited.

Copyrights @ 2016 by Korean Society of Microscopy 
dimensional characterization and limited compositional sensitivity of transmission electron microscopy and limited spatial resolution of secondary ion mass spectrometry. (2) Reflectron which is the devices that can deflect the ion trajectory to have a longer flight path (1 of equation 1 ) have been developed. A longer flight path increases the ToF of the ions towards the detector. Thus, it is possible to have ions of the same mass-to-charge but with different energies arrive at the detector with a similar time-of-flight. This is often termed energy compensation (Gault et al., 2012). (3) Focused ion beam instruments offer the ability to fabricate a site-specific needle-shaped specimen from any solid material. Any region of interest including grain boundary, interfaces of nanoelectronic devices can be positioned in the vicinity of the specimen's apex. (4) Laser pulsing has expanded applications from metallic specimens to semiconducting, even insulating, geological materials, and organics. Thermal pulsing induced by laser energy help to overcome the specimen fracture, i.e., increase in the yield of successful analyses, due to lower the effective evaporation field. Recent development of shorter wavelength in commercial atom probe system makes it possible to achieve the small time-of-departure spread, which translates into high mass resolving power (MRP). However, the evaporation mechanism in pulsed-laser atom probe has not clearly defined because complex physical processes are involved in the interaction between laser pulse and a specimen.

Here, the objective of this paper is to provide a suggestion to choose proper experimental parameters, such as pulse rate, base temperature, detection rate, laser pulse energy, to get good data quality with high success yield depending on specimen. Different types of specimen usually do not perform similarly under APT analysis conditions. We also provide several considerations to achieve reliable data set and the existing challenges in the APT field.

\section{IMPROVEMENT OF QUALITY OF ATOM PROBE DATA}

The atom-by-atom reconstructions provided by APT are uniquely powerful, but the technique has its limitation. It is important to take these into account when interpreting of atom probe data. Known limitations include: (1) detector and optical limitations, (2) reconstruction errors, (3) trajectory aberrations in monophase material, (4) local magnification in polyphaser materials (Larson et al., 2013a, 2013b).

\section{PEAK IDENTIFICAION OF MASS SPECTRUM FOR QUANTITATIVE APT ANALYSIS}

The ranging of mass spectrum is a critical stage of the analysis because it has a significant impact on analytical results.
Peak identification of mass spectrum affects all aspects of the analysis including atomic distribution (shape of cluster/ interface) and bulk composition. There is no existing rule to define mass ranges which are manually defined based on individual experience. Atom probe community have recently been started to establish standards to reach a consensus to define the mass ranges.

The three main considerations for better analytical results are molecular ions, multiple events, and peak overlap. These issues often occur during carbide (Thuvander et al., 2011), nitride (Tang et al., 2010), silicide (Kinno et al., 2012) analysis compared to metallic materials since the evaporation of molecular ions and multiple events where more than one ion originating from the same pulse is detected. In cases where two or more types of ions have very similar mass-to-chargeratios, peaks can overlap. For the carbide, this may be due to a high ionization energy of carbon and/or different bonding energy between metallic atoms and between neighboring carbon atoms or carbon and metal atoms. The requirement of higher electric filed for field evaporation of carbon cause the occurrence of both molecular ion and multiple events. The main controllable factor governing the multiple events is detection efficiency of the APT system (limited capability of the detector). For example, the instrument of LEAP 3000X HR (formerly Imago, CAMECA, USA) whose detection efficiency is $\sim 37 \%$ has 50 ps of timing resolution, but if ions hit close in space they have to be separated by more than 3 ns to be separated (Thuvander et al., 2012). It makes the accuracy of concentration measurements significantly reduce due to undetected ions hit the detector during dead time. So far, in many studies the obtained carbon concentration from carbides through APT was lower than expected from the known stoichiometry because of above issues. Although new detector technology comes along to improve its capacity to resolve multiple events (Costa et al., 2005), it is not a good approach in terms of cost and detection rate. Unless new generation detector is developed, the alternative way is to modify the peak identification method, and one typical method is by using only the ${ }^{13} \mathrm{C}$ isotope. The ${ }^{13} \mathrm{C}$ isotope can be used to calculate how much carbon should be present at $6 \mathrm{Da}$ and $12 \mathrm{Da}$, assuming that the dead time has negligible influence on the ${ }^{13} \mathrm{C}$ peaks. The details are described in reference (Angseryd et al., 2011; Thuvander et al., 2011). In here, the background subtraction is important because the signal to ratio of ${ }^{13} \mathrm{C}$ peaks is relatively high.

Another issue about carbon analysis is overlap between $\mathrm{C}_{2}{ }^{+}, \mathrm{C}_{4}{ }^{2+}$ and $\mathrm{Ti}^{2+}$ at the mass to charge $24 \mathrm{Da}$ in case of the analysis the $\operatorname{Ti}(\mathrm{C}, \mathrm{N})$. The correction of $24 \mathrm{Da}$ peak is usually used a titanium isotope. Carbon and titanium peaks could be decomposed by using $\mathrm{Ti}^{2+}$ isotope peaks at $23\left({ }^{46} \mathrm{Ti}^{2+}\right)$ and $23.5\left({ }^{47} \mathrm{Ti}^{2+}\right)$ Da which do not have any other predicted overlaps. However, the multiple events and the dead time of 
the detector affect the 24 Da peak, so that peak decomposition according to the natural abundance of Ti always yield small amount of ${ }^{12} \mathrm{C}^{+}$. To solve this problem, correction of the peak at $24 \mathrm{Da}$ using single and multiple event spectra were proposed (Angseryd et al., 2011).

Fig. 1 shows multiple events has high portion at $24 \mathrm{Da}$ in the mass spectrum of $\operatorname{Ti}(\mathrm{C}, \mathrm{N})$, which cause a loss of carbon concentration. Light green line shows single events and dark line represents multiple events. The big difference at $24 \mathrm{Da}$ peak demonstrates that the loss of detected ions by multiple events is significant. Because the multiple events should exhibit the same abundance distribution as the single events, the corrected counts of multiple events at $24 \mathrm{Da}(24 \mathrm{Da})_{c-\mathrm{m}}$ can be expressed as:

$$
(24 D a)_{\mathrm{c}-\mathrm{m}}=(24 D a)_{\mathrm{s}} \frac{\left({ }_{46} T i^{2+}+{ }_{47} T i^{2+}\right)_{\mathrm{m}}}{\left({ }_{46} T i^{2+}+{ }_{47} T i^{2+}\right)_{\mathrm{s}}} \cdots \cdots(2)
$$

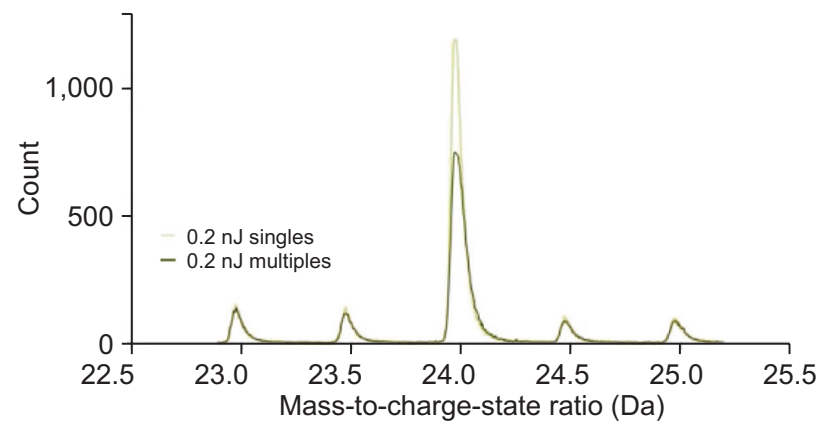

Fig. 1. Single events and multiple events at 24 Da peak of $\operatorname{Ti}(C, N)$ investigated with laser pulse energy of $0.2 \mathrm{~nJ}$. This is constructed with the IVAS software. The light green line represents the single events and the dark line represents multiple events. The amount of ${ }^{12} \mathrm{C}_{2}{ }^{+}$ions missed by the detector is estimated by using the spectra of single and multiple events as shown equation 2. Reprinted from the article of Angseryd et al. (2011) (Ultramicroscopy 111, 609-614) with original copyright holder's permission.
Finally, the amount of ions missed by the detector is able to be calculated by the difference the recorded multiple counts and corrected counts of multiple events, it allows better quantitative analysis.

\section{LOCAL MAGNIFICATION EFFECT}

Sometimes the 3D atom map from APT results is different with original structure. Except imperfection in the reconstruction procedure, one of the most significant factors that influence the discrepancies is deflections in the flight of the ions. It is now well established that the spatial resolution is strongly degraded by the so-called local magnification effects in two-phase alloys since it can lead to trajectory overlaps close to interfaces between phases (Geuser et al., 2007; Miller et al., 1996; Phippe et al., 2010; Vurpillot et al., 2000). Local magnification effect is prominent when the difference of evaporation field between precipitates and surrounding matrix is remarkable. As shown in Fig. 2, when precipitates have a lower evaporation field than matrix, the atoms at precipitates region are preferentially field evaporated and the precipitate region is flattened on the surface. It makes ion trajectories deflect inwards, which causes an increase in the local density in the precipitates region. Conversely, in the case of high-field precipitates, a protuberance at the tip surface causes an apparent decrease in the atomic density in reconstructed images (Gault et al., 2012).

Simulations have recently been performed to investigate reconstruction artifacts resulting local magnification effects associated with trajectory aberration by precipitates (Larson et al., 2013a, 2013b). Fig. 3A and B show the simulation results of low field precipitates $(\varepsilon=0.5)$ and high field precipitates $(\varepsilon=2.0)$, respectively. The $\varepsilon$ is a ratio of the evaporation field of the atoms within the precipitates to those within the matrix

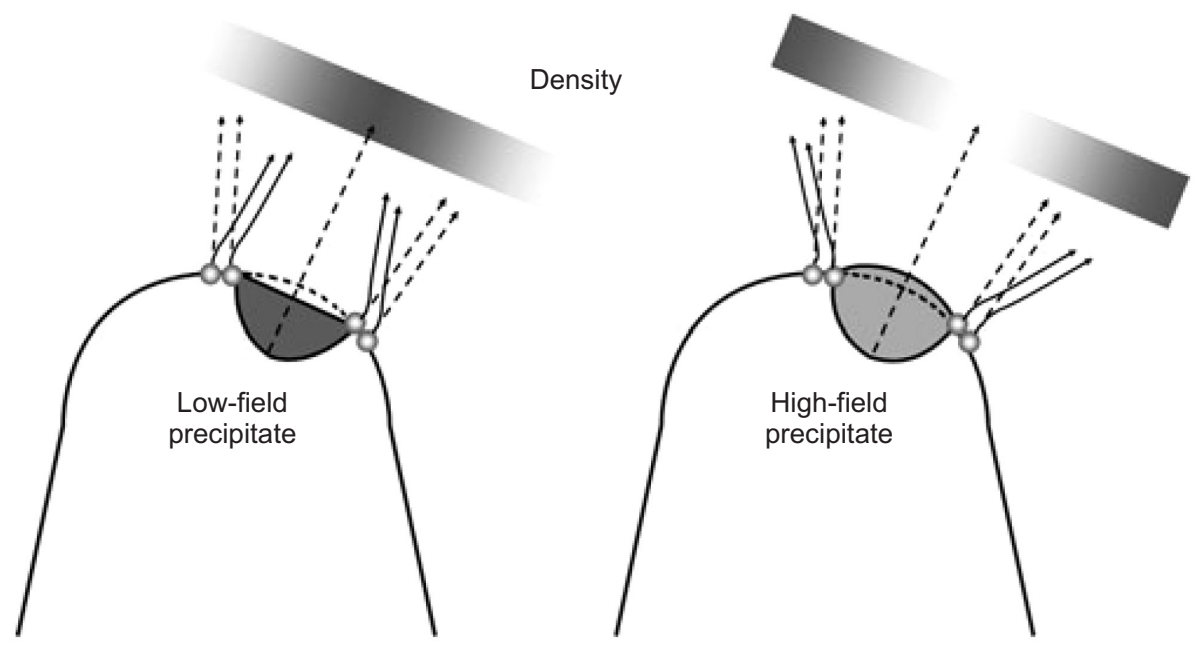

Fig. 2. Trajectory aberrations induced by a low- and high-field precipitate. This results in a change of surface curvature and atomic density in reconstructed images. Reprinted from the book of Gault et al. (2012) (Springer, New York) with original copyright holder's permission. 

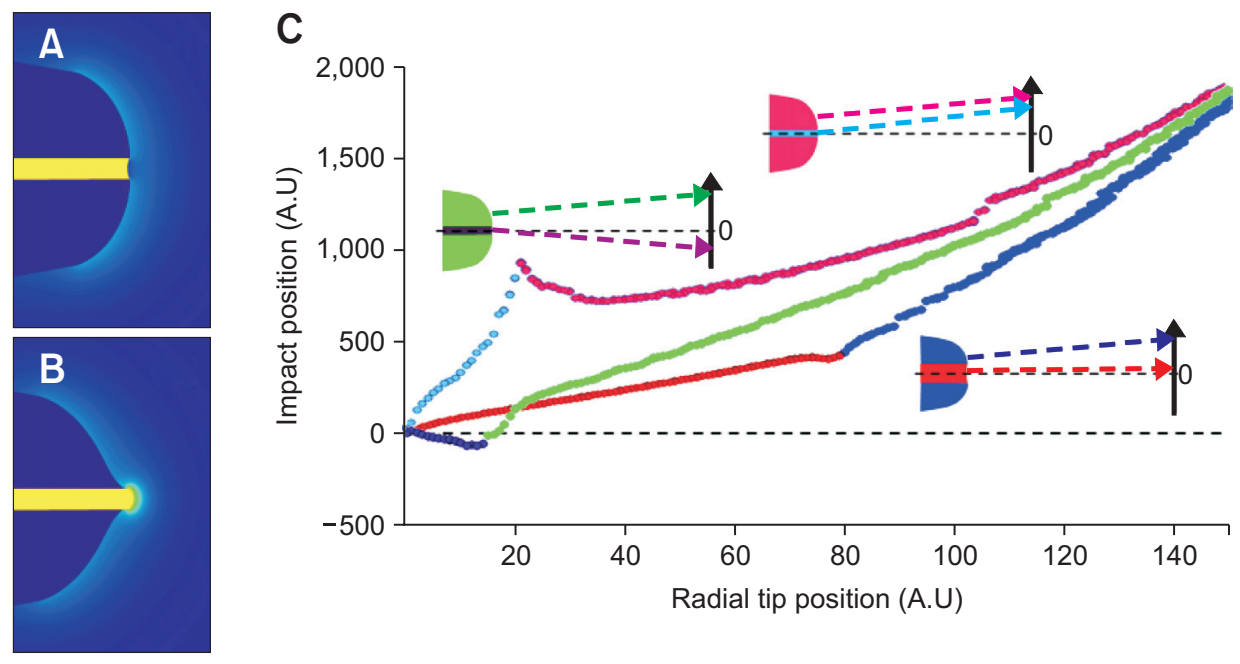

Fig. 3. Simulated local curvature and distribution of the electrostatic field for embedded precipitates (yellow) of $\varepsilon=0.5$ (A) and $\varepsilon=2.0$ (B). (C) Impact position on the detector as a function of the radial tip position at the specimen surface for cylindrical precipitate with $r_{p} \sim 3$ and $\varepsilon=2.0$ (cyan and pink), $\mathrm{r}_{\mathrm{p}} \sim 16$ and $\varepsilon=0.55$ (red and blue), and $\mathrm{r}_{\mathrm{p}} \sim 3$ and $\varepsilon=0.55$ (purple and green). Reprinted from the article of Larson et al. (2013a) (Curr. Opin. Solid State Mat. Sci. 17, 236-247) with original copyright holder's permission.
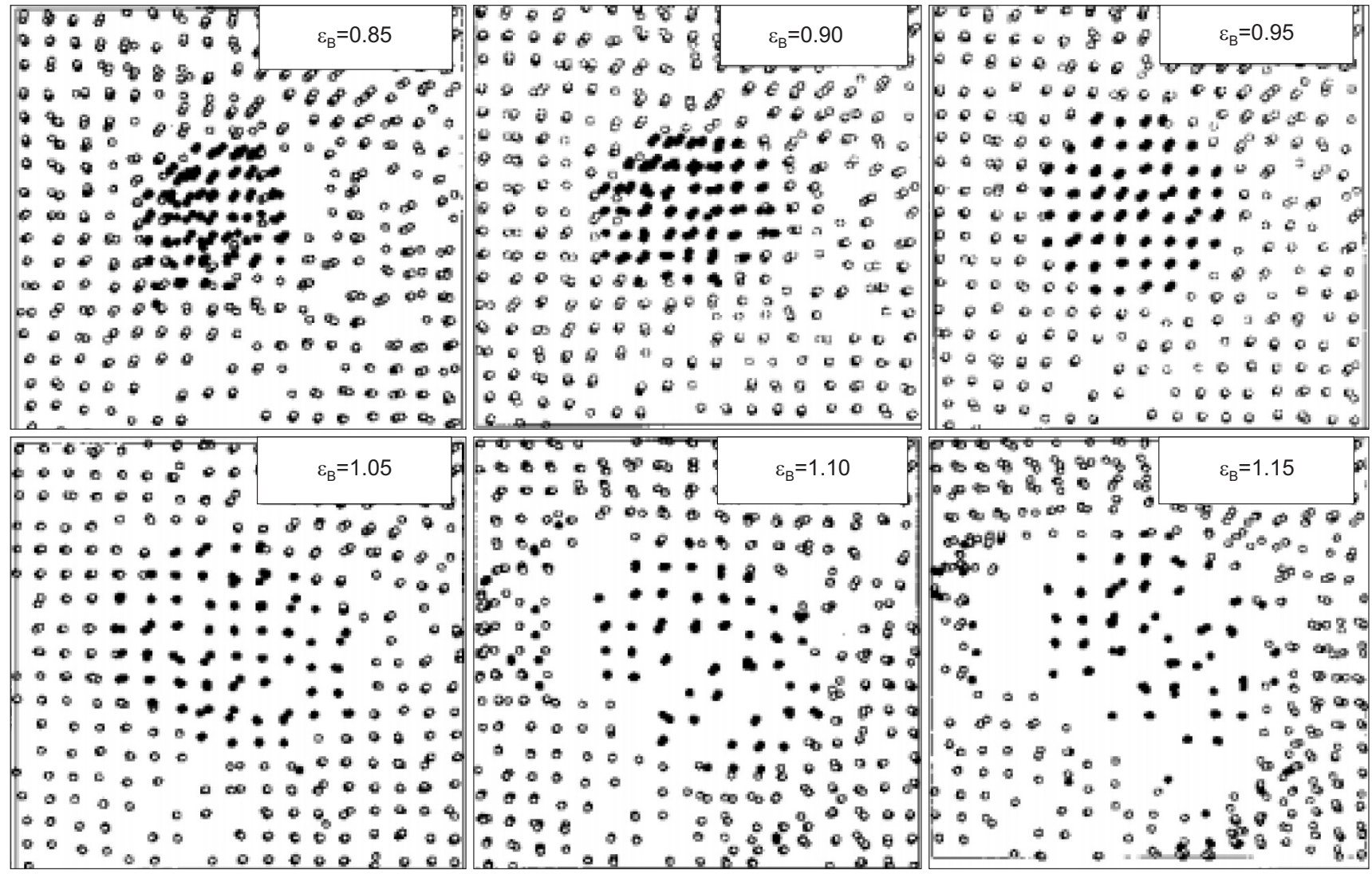

Fig. 4. Reconstructed precipitates investigated by simulation of ion trajectories with $\varepsilon_{\mathrm{B}}$ ranging from 0.85 to 1.15 . Spherical precipitates containing only $\mathrm{B}$ atoms (black) embedded in pure A solid solution (gray) were considered. Reprinted from the article of Vurpillot et al. (2000) (Appl. Phys. Lett. 76, 31273129) with original copyright holder's permission.

(i.e., $\mathrm{E}_{\mathrm{p}}=\varepsilon \mathrm{E}_{\mathrm{M}}$ ). In both case, cylindrical precipitate (yellow) is surround in the matrix. These results are consistent with as explained in Fig. 2. In addition, Fig. 3C demonstrates the local magnification effect is also dependent on the size of precipitates. The graph indicates that impact position on the detector as a function of the radial position at the specimen surface. The radius $\left(\mathrm{r}_{\mathrm{p}}\right)$ and $\varepsilon$ of precipitates for cyan is 3 $\mathrm{nm}, 2.0$, for purple is $3 \mathrm{~nm}, 0.55$, and for red is $16 \mathrm{~nm}, 0.55$, respectively. Note that the negative slop (in pink, purple) results in the trajectory overlap and deformation of the reconstruction of precipitates.

Fig. 4 shows a series of cross sections of reconstructed 
precipitates (black atoms) for the relative evaporation field of precipitates $\left(\varepsilon_{\mathrm{B}}\right)$ ranging from 0.85 to 1.15 using a simulation of ion trajectories (Vurpillot et al., 2000). The deflection of ion trajectories caused by the precipitates affects both an atomic density in the precipitate region and the morphologies (shape and size) on the detector. In the case of low evaporation field of precipitates the density of reconstructed precipitates is high, but the density is decreased with increasing values of $\varepsilon_{\mathrm{B}}$. These aberrations are limited to atoms near the interface over distances close to three interatomic distances. Although $3 \mathrm{D}$ reconstruction procedure has been proposed to overcome the local magnification, the application is limited (Gault et al., 2011; Marquis \& Vurpillot, 2008; Oberdorfer \& Schmitz, 2011). For example, the modified $3 \mathrm{D}$ reconstruction algorithm is applied to an AlZnMg alloy containing $\mathrm{Zn}$ - and Mg-rich particles (Geuser et al., 2007). As shown Fig. 5A, the precipitates whose evaporation field is lower than that of the
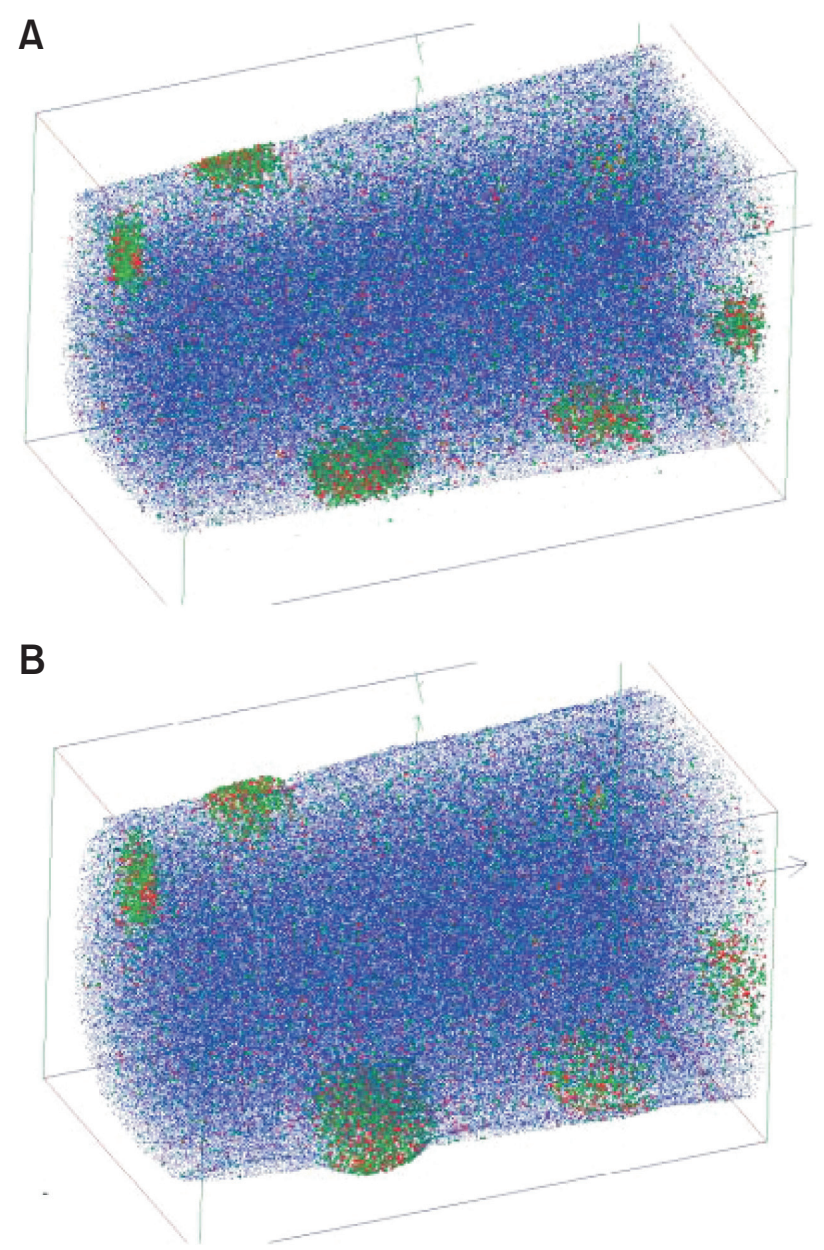

Fig. 5. Three-dimensional reconstruction of precipitates in AlZnMg alloy when standard reconstruction procedures (A) and improved algorithm (B) are applied. The shape and atomic density of precipitates are modified. Reprinted from the article of Geuser et al. (2007) (Surf. Interface Anal. 39, 268-272) with original copyright holder's permission. matrix have ellipsoidal shapes when standard reconstruction procedures are used. After application of improved algorithm as Fig. 5B, the shape of the precipitates is more spheroidal and the atomic density becomes homogeneous.

\section{OPTIMIZATION OF EXPERIMENTAL PARAMITERS}

The data quality including MRP, background, ratio of multiple events, and complex ion generation is dependent on selection of experimental parameters such as base temperature, detection rate, pulse rate, laser pulse energy, and voltage. In order to improve the data quality, understanding how these experimental parameters influence on data collection is important.

MRP is generally defined as $\mathrm{m} / \Delta \mathrm{m}$, where $\Delta \mathrm{m}$ is the width of the peak at half of peak height, so called full-width at halfmaximum. It should be high value for good accuracy of the elemental identification. Better MRP is normally achieved by lower base temperature, lower detection rate, and higher pulse energy. In laser pulsing mode, cooling time is the main parameter governing the MRP. MRP is reduced when the cooling time become longer, i.e., the specimen does not cool sufficiently to the base temperature between pulse, because of delayed field evaporation at the tip surface under the residual elevated temperature (Bachha et al., 2011; Seol et al., 2016b; Vella et al., 2011). Indeed, increasing thermal tails were observed in the spectra with extremely increasing laser energy. Fig. 6 indicates the influence of laser pulsed energies on field evaporation of high-k dielectric $\mathrm{LaAlO}_{3}$ (Kim et al., 2016). Note that many other materials can follow other tendency with such a ceramic material.

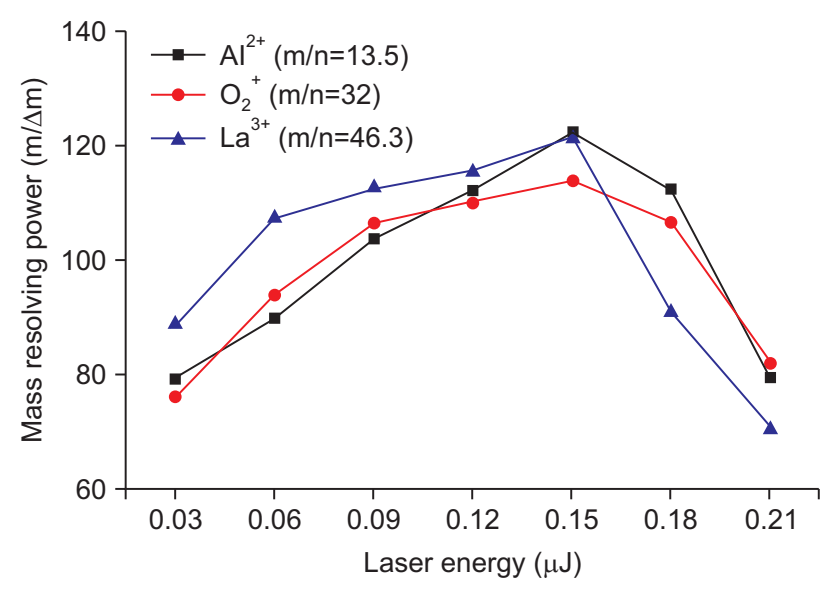

Fig. 6. Mass resolving power $(\mathrm{m} / \Delta \mathrm{m})$ of $\mathrm{Al}^{2+}, \mathrm{O}_{2}{ }^{+}, \mathrm{La}^{3+}$ as a function of laser pulse energy ranging from 0.03 to $0.21 \mu \mathrm{J}$. Extremely high laser pulse energy leads to delayed field evaporation of triggering the $\mathrm{LaAlO}_{3}$ ions at the tip surface. Reprinted from the article of Kim et al. (2016) (Microsc. Microanal. 22(Suppl 3), 1605-1605) with original copyright holder's permission. 
In addition to MRP, the signal-to-background ratio also reveals the quality of a mass spectrum. A lower signal-tobackground ratio induces the disappearance of isotope peak and extremely small amount of elements peak (lower than a few ppb). A low level of background can be usually obtained by low base temperature, high detection rate, high pulse rate, and high laser pulse energy. However, there is a trade-off between data quality and analysis yield. The low base temperature and high detection rate for low signalto-background ratio leads to an increase of the specimen fracture. To achieve high success yield and good data quality simultaneously, subtraction of the background and depth scale correction have been proposed (Multas et al., 2011).

The most considerable trade-off issue in laser-pulsing mode is laser pulse energy. Although high laser pulse energy generally results in high success yield, better MRP, and low background, extreme high energy leads to surface migration, complex ion generation, and nonuniform spatial evaporation behavior. The stoichiometry deficiency observed in APT analyses of nitrides and oxide at high laser pulse energy is well known (Devaraj et al., 2013; Kinno et al., 2014; Santhangopalan et al., 2015). For example, in the case of $\mathrm{GaN}$, at the lowest laser energies, the apparent composition is nitrogen-rich, while higher laser energies results in gallium-rich (i.e., nitrogen-deficient) (Gu et al., 2013; Riley et al., 2014; Sanford et al., 2014). The origin of this trend is controversial until now, but one widely proposed interpretation is the formation of a significant amount of neutral $\mathrm{N}_{2}$ gas molecules at low electric field (high laser energy) (Diercks et al., 2013; Gault et al., 2016). In addition to oxide and nitride, laser-dependent APT measured stoichiometry have been demonstrated for other compound semiconductors such as $\mathrm{Cu}(\mathrm{In}, \mathrm{Ga}) \mathrm{Se}_{2}, \mathrm{CdTe}, \mathrm{Ge}_{2} \mathrm{Sb}_{2} \mathrm{Te}_{5}$ (Chae et al., 2016; Choi et al., 2011; Larson et al., 2012).

\section{SUMIMARY AND CONCLUSIONS}

Our brief comments provide expanded opportunities for APT applications in service environments, a characterization of key interest to the materials community. Correct interpretation of APT data sets including mass resolution, signal-tobackground ratios, and local elemental variations is the most important. Because APT analysis parameters play a significant role in the APT-measured compositional accuracy and reconstruction precision, we must optimize the parameters for each materials of interest.

\section{CONFLICT OF INTERST}

No potential conflict of interest relevant to this article was reported.

\section{ACKNOWLEDGMENTS}

The authors are grateful for financial support from the National Institute for Nanomaterials Technology (NINT) in POSTECH. We thank S.-Y. Na (POSTECH).

\section{REFERENCES}

Angseryd J, Liu F, Andrén H O, Gerstal S S A, and Thuvander M (2011) Quantitative APT analysis of Ti(C,N). Ultramicroscopy 111, 609-614.

Bachha M N, Danoix R, Vurpillot F, Hannoyer B, Ogale S B, and Danoix F (2011) Evidence of lateral heat transfer during laser assisted atom probe tomography analysis of large band gap materials. Appl. Phys. Lett. 99, 084101.

Bang C W, Seol J B, Yang Y S, and Park C G (2015) Atomically resolved cementite dissolution governed by the strain state in pearlite steel wires. Scripta Mater. 108, 151-155.

Chae B G, Seol J B, Song J H, Jung W Y, Hwang H, and Park C G (2016) Atomic-scale quantification of interdiffusion and dopant localization in GeSbTe-based memory devices. Appl. Phys. Lett. 109, 112103.

Choi P, Cojocaru-Mirédin O, Wuerz R, and Raabe D (2011) Comparative atom probe study of $\mathrm{Cu}(\mathrm{In}, \mathrm{Ga}) \mathrm{Se}_{2}$ thin-film solar cells deposited on soda-lime glass and mild steel substrates. J. Appl. Phys. 110, 124513.

Costa G D, Vurpllot F, Bostel A, Bouet M, and Deconihout B (2005) Design of a delayline position-sensitive detector with improved performance. Rev. Sci. Instrum. 76, 013304.

Devaraj A, Colby R, Hess W P, Perea D E, and Thevuthasan S (2013)
Role of photoexcitation and field ionization in the measurement of accurate oxide stoichiometry by laser-assisted atom probe tomography. J. Phys. Chem. Lett. 4, 993-998.

Diercks D R, Gorman B P, Kirchhofer R, Sanford N, Betness K, and Brubaker M (2013) Atom probe tomography evaporation behavior of C-axis GaN nanowires: crystallographic, stoichiometric, and detection efficiency aspects. J. Appl. Phys. 114, 184903.

Gault B, Loi S T, Araullo-Peters V J, Stephenson L T, Moody M P, Shrestha S L, Marceau R K W, Lan Y, Cairney J M, and Ringer S P (2011) Dynamic reconstruction for atom probe tomography. Ultramicroscopy 111, 1619-1624.

Gault B, Moody M P, Cairney J M, and Ringer S P (2012) Atom Probe Microscopy (Springer, New York).

Gault B, Saxey D W, Ashton M W, Sinnott S B, Chiaramonti A N, Moody M P, and Schreiber D K (2016) Behavior of molecules and molecular ions near a field emitter. New J. Phys. 18, 033031.

Geuser F D, Lefebvre W, Danoix F, Vurpillot F, Forbord B, and Blavette D (2007) An improved reconstruction procedure for the correction of local magnification effects in three-dimensional atom-probe. Surf. Interface Anal. 39, 268-272. 
Gordon L M and Joester D (2011) Nanoscale chemical tomography of buried organic-inorganic interfaces in the chiton tooth. Nature $\mathbf{4 6 9}$, 194-197.

Gu G H, Jang D H, Nam K B, and Park C G (2013) Composition fluctuation of in and well-width fluctuation in InGaN/GaN multiple quantum wells in light-emitting diode devices. Microsc. Microanal. 19 Suppl 5, 99104.

Karlsson J, Sundell G, Thuvander M, and Andersson M (2015) Atomically resolved tissue integration. Nano Lett. 14, 4220-4223.

Kelly T F and Miller M K (2007) Atom probe tomography. Rev. Sci. Instrum. 78, 031101.

Kim J H, Byun T S, Shin E, Seol J B, Young S, and Reddy N S (2015) Smal angle neutron scattering analyses and high temperature mechanical properties of nano-structured oxide dispersionstrengthened steels produced via cryomilling. J. Alloys Compd. 651, 363-374.

Kim Y T, Seol J B, Kwak C M, and Park C G (2016) Influence of laserpulsed energies on field evaporation of $\mathrm{LaAlO}_{3}$ in atom probe tomography analysis. Microsc. Microanal. 22(Suppl 3), 1605-1605.

Kinno T, Akutsu H, Tomita M, Kawanaka S, Sonehara T, Hokazono A, Renaud L, Martin I, Benbaalagh R, Sallé B, and Takeno S (2012) Influence of multi-hit capability on quantitative measurement of NiPtSi thin film with laser-assisted atom probe tomography. Appl. Surf. Sci. 259, 726-730.

Kinno T, Tomita M, Ohkubo T, Takeno S, and Hono K (2014) Laserassisted atom probe tomography of ${ }^{18} \mathrm{O}$ enriched oxide thin film for quantitative analysis of oxygen. Appl. Surf. Sci. 290, 194-198.

Larson D J, Gault B, Geiser B P, Geuser F D, and Vuppilot F (2013a) Atom probe tomography spatial reconstruction: status and directions. Curr. Opin. Solid State Mat. Sci. 17, 236-247.

Larson D J, Prosa T, Ulfig R M, Geiser B P, and Kelly T F (2013b) Local Electrode Atom Probe Tomography (Springer, New York).

Larson D J, Reinhard D A, Prosa T J, Olson D, Lawrence D, Clifton P H, Ulfig R M, Kelly T F, and Smentkowski V S (2012) Atom probe tomography analysis of grain boundaries in CdTe. Microsc. Microanal. 18(Suppl 2), 928-929.

Marquis E A and Vurpillot F (2008) Chromatic aberrations in the field evaporation behavior of small precipitates. Microsc. Microanal. 14, 561-570.

Miller M K, Cerezo A, Hetherington M G, and Smith G E W (1996) Atom Probe Field lon Microscopy (Clarendon Press, Oxford).

Miller M K and Forbes F R G (2014) Atom Probe Microscopy (Springer, New York).

Multas S, Klein C, and Gerstl S S A (2011) Investigation of the analysis parameters and background subtraction for high-k materials with atom probe tomography. Ultramicroscopy 111, 546-551.

Narayan K, Prosa T J, Fu J, Kelly T F, and Subramaniam S (2012) Chemical mapping of mammalian cells by atom probe tomography. J. Struct. Biol. 178, 98-107.

Oberdorfer C and Schmitz G (2011) On the field evaporation behavior of dielectric materials in three-dimensional atom probe: a numeric simulation. Microsc. Microanal. 17, 15-25.

Park H S, Seol J B, Lim N S, Kim S I, and Park C G (2015) Study of the decomposition behavior of retained austenite and the partitioning of alloying elements during tempering in CMnSiAl RIP steels. Mater. Des. 82, 173-180.

Phippe T, Gruber M, Vurpillot F, and Blavette D (2010) Clustering and local magnification effects in atom probe tomography: a statistical approach. Microsc. Microanal. 16, 643-648.
Riley J R, Detchprohm T, Wetzel C, and Lauhon L J (2014) On the reliable analysis of indium mole fraction within $\mathrm{In}_{\mathrm{x}} \mathrm{Ga} 1_{-\mathrm{x}}$ Nquantum wells using atom probe tomography. Appl. Phys. Lett. 104, 152102.

Sanford N A, Blanchard P T, Brubaker M, Bertness K A, Roshko A, Schlager J B, Kirchhofer R, Diercks D R, and Gorman B (2014) Laser assisted atom probe tomography of MBE grown GaN nanowire heterostructures. Phys. Status Solidi C 11, 608-612.

Santhangopalan D, Schreiber D K, Perea D E, Martens R L, Janssen Y, Khalifah P, and Meng Y S (2015) Effects of laser energy and wavelength on the analysis of $\mathrm{LiFePO}_{4}$ using laser assisted atom probe tomography. Ultramicroscopy $\mathbf{1 4 8 , 5 7 - 6 6}$

Seol J B, Gu G H, Lim N S, Das S, and Par C G (2010) Atomic scale investigation on the distribution of boron in medium carbon steels by atom probe tomography and EELS. Ultramicroscopy 110, 783-788.

Seol J B, Jung J E, Jang Y W, and Park C G (2013a) Influence of carbon content on the microstructure, martensitic transformation and mechanical properties in austenite/ $\varepsilon$-martensite dual-phase $\mathrm{Fe}$ Mn-C steels. Acta Mater. 61, 558-578.

Seol J B, Kim Y T, Kim B H, and Park C G (2016a) Novel approach for observing the asymmetrical evolution and the compositional nonuniformity of laser pulsed atom probe tomography of a single ZnO nanowire. Met. Mater. Int. 22, 34-40.

Seol J B, Kwak C M, Kim Y T and Park C G. (2016b) Understanding of the field evaporation of surface modified oxidematerials through transmission electron microscopy and atom probetomography. Appl. Surf. Sci. 368. 368-377.

Seol J B, Lee B H, Chop P, Lee S G, and Park C G (2013b) Combined nano-SIMS/AFM/EBSD analysis and atom probe tomography, of carbon distribution in austenite/ $\varepsilon$-martensite high-Mn steels. Ultramicroscopy 132, 248-257.

Seol J B, Lim N S, Lee B H, Renaud L, and Par C G (2011) Atom probe tomography and nano secondary ion mass spectroscopy investigation of the segregation of boron at austenite grain boundaries in $0.5 \mathrm{wt} . \%$ carbon steels. Met. Mater. Int. 17, 413-416.

Seol J B, Raabe D, Choi P, Im Y R, and Park C G (2012) Atomic scale effects of alloying, partitioning, solute drag and austempering on the mechanical properties of high-carbon bainitic-austenitic TRIP steels. Acta Mater. 60, 6183-6199.

Seol J B, Raabe D, Choi P, Park H S, Kwak J H, and Park C G (2013c) Direct evidence for the formation of ordered carbides in a ferritebased low-density $\mathrm{Fe}-\mathrm{Mn}-\mathrm{Al}-\mathrm{C}$ alloy studied by transmission electron microscopy and atom probe tomography. Scripta Mater. 68, 348-353.

Tang F, Gault B, Ringer S P, and Cairney J M (2010) Optimization of pulsed laser atom probe (PLAP) for the analysis of nanocomposite TiSi-N films. Ultramicroscopy 110, 836-843.

Thuvander M, Kvist A, Johnson L J S, Weidow J, and Andrén H O (2012) Reduction of multiple hits in atom probe tomography. Ultramicroscopy 132, 81-85.

Thuvander M, Weidow J, Angseryd J, Falk L K L, Liu F, Sonestedt M, Stiller K, and Andrén H O (2011) Quantitative atom probe analysis of carbides. Ultramicroscopy 111, 604-608.

Vella A, Mazumder B, Costa G D, and Deconihout B (2011) Field evaporation mechanism of bulk oxides under ultra fast laser illumination. J. Appl. Phys. 110, 044321.

Vurpillot F, Bostel A, and Blavette D (2000) Trajectory overlaps and local magnification in three-dimensional atom probe. Appl. Phys. Lett. 76, 3127-3129. 